\title{
Selective leaching of copper from waste printed circuit boards (PCBs) using glycine as a complexing agent
}

\author{
Mokhlis H.*, Daoudi R.D. and Azzi M. \\ Casablanca, 5366, Morocco. \\ Received: 21/06/2020, Accepted: 21/01/2021, Available online: 22/02/2021 \\ *to whom all correspondence should be addressed: e-mail: hicham.mokhlis@gmail.com \\ https://doi.org/10.30955/gnj.003361
}

Laboratory of Interface Materials and Environment (LIME), Faculty of Sciences Aîn Chock, Hassan II University of Casablanca, Maarif,

\section{Graphical abstract}

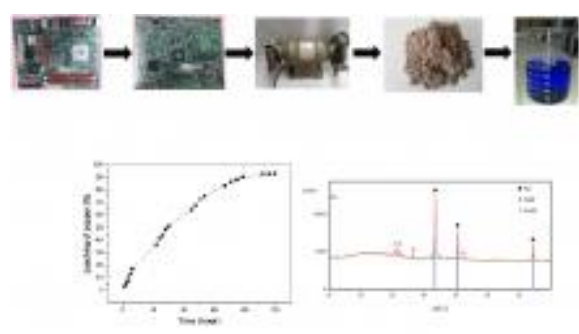

\begin{abstract}
In this research, the selective leaching of copper from waste printed circuit boards (PCBs) using glycine as a complexing agent was investigated. PCBs were pulverized and sieved, which allowed obtaining a PCBs powder of particle size fraction $\leq 1 \mathrm{~mm}$. The PCBs powder has been characterized by several techniques before and after leaching. In order to understand the copper extraction process, the reaction mechanisms, and to determine the optimal leaching parameters, the effects of a range of parameters during copper leaching were investigated, including leaching time, solid-to-liquid ratio, mechanical stirring rate, leaching temperature and glycine concentration. Copper leaching from PCBs waste powder was identified as a complex four-stage gas-liquid-solid process that is carried out slowly under ambient conditions. Glycine shows a very significant selectivity for copper during leaching process allowing dissolving copper from PCBs waste with a percentage of $92.8 \%$ under ambient conditions.
\end{abstract}

Keywords: Copper recovery, WEEE, hydrometallurgy, PCB, glycine, selective leaching.

\section{Introduction}

According to the latest alarming report from the United Nations University (UNU) published in 2020 (Baldé et al., 2020), the production of waste electrical and electronic equipment (WEEE) reached a new world record with 53.6 million tonnes discarded in 2019 and is projected to grow to 74.7 million tonnes by 2030 . In fact WEEE is considered to be one of the fastest growing types of solid waste in the world with an annual increase of 3 to $5 \%$ (Bigum et al., 2012; Cui and Zhang, 2008; Kiddee et al., 2013). The UNU study also estimates the value of all waste discarded in 2019 to 57 billion USD, because of the precious metals they contain, in addition to the various recyclable plastics. WEEE is a true source of metals, e.g. $0.1 \% \mathrm{Au}, 0.2 \% \mathrm{Ag}, 20 \% \mathrm{Cu}$ and $4 \%$ Sn (Havlik et al., 2010). So, we can conclude that the recovery of metals from WEEE is a vitally important issue.

Among the most useful WEEE to be treated are printed circuit boards (PCBs). PCBs are mainly composed of nonmetals, in particular plastics, glass fibers, and ceramics with a percentage of around $70 \%$, and metals such as copper, nickel, gold, and tin for the remaining 30\% (Goosey and Kellner, 2003). Although the composition of PCBs varies according to their age, origin and manufacturer, copper remains one of the metals with the highest percentage in PCBs (Kim et al., 2011; Oishi et al., 2007; Oguchi et al., 2011; Salhofer and Tesar, 2011; Tuncuk et al., 2012) . PCBs generally contain 10 - 30\% of copper (Oishi et al., 2007).

There are several methods for metal recovery from PCBs, such as physical and mechanical separation (Guo et al.,2011; Duan et al., 2009), pyrometallurgical methods (Havlik et al., 2010; Yang et al.,2013), hydrometallurgical methods (Kim et al., 2011; Oishi et al., 2007; Jha et al., 2012), bio-hydrometallurgical methods (Zhu et al., 2011; Yang et al., 2009), and other methods (Xiu et al., 2013; Zhang et al., 2012; Zhou and Qiu, 2010). Hydrometallurgical methods are effective for the recovery of metals from PCBs, but the consumption of leaching agents, usually acids or bases, is high, generating large quantities of wastewater that must be treated for reuse or released into the environment. These processes have many advantages, such as relatively low investment costs and a low environmental impact in comparison to pyrometallurgical methods (Tuncuk et al., 2012; Jha et al., 2012; Büyükbay et al., 2010).

Waste PCB recycling is a topic that has been widely discussed under several points of view in the scientific literature. Several patents have focused on the extraction 
of metals from PCBs. Two types of metal extraction processes have been used in the patents: the hydrometallurgical route, including the exploitation of biological methods, and the pyrometallurgical one (Rocchetti et al., 2018). In patents based on hydrometallurgical processes, the leaching of metals can be achieved by using acidic reagents (TW200418731, US2006191376), basic reagents (CN102011008, CN104745 824), oxidizing agents (CN102329960, JP2015004135) and also by exploiting the metabolism of microorganisms (bioleaching) (CN103898550, CN104328280).

However, the challenge is very great in the particular case of copper recovery, because of the heterogeneity of the materials used in the electrical and electronic equipment (EEE) manufacturing process. In fact complexity is a common characteristic of all EEEs, for example in a simple mobile phone, there can be between 500 and 1000 different substances (Singhal, 2005). Therefore, the choice of the leaching solution is essential. The dissolution must be as selective as possible: the solution must dissolve the valuable elements but be consumed as little as possible by the uninteresting elements. Among the most commonly used leaching solutions are inorganic acids such as $\mathrm{HCl}$, $\mathrm{H}_{2} \mathrm{SO}_{4}$ and $\mathrm{HNO}_{3}$. These acids allow the extraction of $\mathrm{Cu}$ from PCBs in high percentages (Masavetas et al., 2009; Vijayaram and Chandramohan, 2013). However, the separation process becomes complicated when it comes to a mixture of metals, as is the case for PCBs, because of the poor selectivity of inorganic acids. In response to this problem, several researchers have been interested in the recovery of copper in ammonia environment (Oishi et al., 2007; Koyama et al., 2006a; Koyama et al., 2006b; Xiao et al., 2013; Sun et al., 2015), whose use should be more appropriate as long as it is more selective for copper and would not require pre-separation and elimination of other species. However, despite its high selectivity for copper, the use of ammonia as a complexing agent has a number of disadvantages, mainly related to its volatility and toxicity. We, therefore, thought it would be interesting to study other complexing, non-volatile species that could play the same role as ammonia in leaching solutions. We have therefore chosen to use the simplest and cheapest amino acid, which is glycine.

Several researchers have been interested in the use of glycine as a copper complexing agent. Drissi-Daoudi et al. (2003) have investigated the copper behavior in different cupric complex solutions; they found that in the case of glycine, cyclic voltammetry shows two cathodic peaks and one oxidation peak. They also found that the cuprous complex is an intermediate in the cupric complex reduction but it is not detected during the oxidation of the electrodeposited copper. Oraby et al. (2014, 2015, 2017) have also used glycine as lixiviant in alkali environment $(\mathrm{pH}$ = 10.5-11) with different oxidants $\left(\mathrm{O}_{2}, \mathrm{H}_{2} \mathrm{O}_{2}\right.$ and/or $\left.\mathrm{Cu}^{2+}\right)$ and catalyst/synergist (for precious metals) for effectively recovering $\mathrm{Au}, \mathrm{Ag}$ and $\mathrm{Cu}$ from pure foils or minerals. We also have developed a process for selective recovery of copper from waste electrical and electronic equipment (WEEE) in glycine solution (Mokhlis et al., 2018).
The objective of this work is therefore to study the selective recovery of copper from waste printed circuit boards (PCBs) using glycine as a complexing agent. To this end, we proceeded in several steps. First, using various techniques, we characterized the powder that comes from the pulverization of PCBs. Then, in order to understand the copper extraction process and the reaction mechanisms, and to determine the optimal leaching parameters, the effects of a range of parameters during copper leaching were investigated, including leaching time, solid-to-liquid ratio, mechanical stirring rate, leaching temperature and glycine concentration.

\subsection{Background to copper-glycine complexing}

Glycine has a number of advantages over many other copper complexants. It is a non-toxic, inexpensive, ecologically stable, enzymatically destructible reagent, and easily metabolized in most living organisms (Oraby and Eksteen, 2014). Glycine can also improve the solubility of copper ions in aqueous solutions because of its complexing action (Aksu and Doyle, 2002a; Aksu and Doyle, 2002b). As a complexing agent, glycine can exist in aqueous solutions in three different forms (Smith and Martell, 1976): ${ }^{+} \mathrm{H}_{3} \mathrm{NCH}_{2} \mathrm{COOH}\left(\mathrm{H}_{2} \mathrm{~L}^{+}\right.$, cation), ${ }^{+} \mathrm{H}_{3} \mathrm{NCH}_{2} \mathrm{COO}^{-}$(HL, zwitterion), and $\mathrm{H}_{2} \mathrm{NCH}_{2} \mathrm{COO}^{-}$( $\mathrm{L}^{-}$, anion), with $\mathrm{pKa}_{1}=2.350$ and $\mathrm{pKa}_{2}=9.778$.

Glycine can form soluble complexes with both $\mathrm{Cu}$ (II) and $\mathrm{Cu}(\mathrm{I})$ ions. The potential-pH diagram for the copper-waterglycine system (Aksu and Doyle, 2002a) shows that $\mathrm{Cu}$ (II) glycine complex is the thermodynamically stable oxidized form of copper in weak acid and weak alkaline solutions. The stability constants of copper complexes with glycine are listed in Table 1 (Aksu and Doyle, 2002a) and show that $\mathrm{CuL}_{2}$ complex has the highest stability constant (15.64).

Table 1. Stability constants of copper-glycine complexes at $25^{\circ} \mathrm{C}$ and $1 \mathrm{~atm}$

\begin{tabular}{cc}
\hline Reaction & LogK \\
\hline $\mathrm{Cu}^{2+}+\mathrm{L}^{-}=\mathrm{CuL}^{+}$ & 8.57 \\
\hline $\mathrm{Cu}^{2+}+2 \mathrm{~L}^{-}=\mathrm{CuL}_{2}$ & 15.64 \\
\hline $\mathrm{Cu}^{+}+2 \mathrm{~L}^{-}=\mathrm{CuL}_{2}^{-}$ & 10.1 \\
\hline $\mathrm{CuL}^{+}+\mathrm{H}^{+}=\mathrm{CuHL}^{2+}$ & 2.92 \\
\hline
\end{tabular}

Therefore, to induce the formation of the $\mathrm{CuL}_{2}$ complex, we chose in our study to work in a buffer solution (glycine, sodium carbonate) of $\mathrm{pH}=\mathrm{pKa}_{2}=9,78$.

\section{Experimental}

\subsection{Materials and solutions}

The raw material comes from printed circuit boards (PCBs) collected from obsolete computers collected from the various departments of the Aîn Chok Faculty of Science of Casablanca. PCBs are first disassembled manually to remove certain reusable electronic components and heavy parts, such as CPUs, heat dissipaters and capacitors, slots and different connectors. PCBs are then pulverized and sieved, which allows to obtain a PCBs powder of particle size fraction $\leq 1 \mathrm{~mm}$. 
The leaching solution is a mixture of glycine (HiMedia) and sodium carbonate (Sigma-Aldrich). All dilutions are made with distilled water.

\subsection{Experimental set-up and procedures}

\subsubsection{PCBs powder characterization}

The characterization of PCBs powder is carried out using different techniques. X-ray fluorescence spectroscopy analysis (Epsilon $3 \mathrm{X}$ ) and $\mathrm{X}$-ray diffraction analysis (XRD) (Bruker AXS D8) are used to determine the composition of PCBs powder before leaching as well as the composition of the residue obtained after filtering the leaching solution. Surface morphology and chemical composition of PCBs powder before and after leaching are examined by scanning electron microscopy (SEM) and energy dispersive X-ray analyzer (EDS) (JSM-IT100, JEOL, Japan).

\subsubsection{Leaching}

In our study we proceed to the leaching of copper from PCBs powder in the open air, under ambient conditions of temperature and pressure. For each leaching test, a sample of PCBs powder of weight between 1.5 and $15 \mathrm{~g}$ is taken and mixed with $150 \mathrm{~mL}$ of leaching solution (glycine, sodium carbonate) which results in a suspension. Leachate samples are collected at different time intervals to track the evolution of copper leaching over time, using an UV-Vis spectrophotometer (UV-1240 Shimadzu) and an atomic absorption spectrophotometer (Shimadzu AA-6800 series). After each leaching experiment, the suspension (mixture of PCBs powder and leaching solution) is filtered; the residue is dried in oven and then weighed.

The copper leaching percentage is calculated as the ratio of amount of $\mathrm{Cu}$ present in the leachate sample to the initial amount of Cu present in the PCBs powder sample, this ratio is represented by (equation 1 ):

Leaching of copper \%

$=\frac{\text { Amount of Cu in leachate sample }}{\text { Initial amount of Cu in PCBs powder }} \times 100$

\section{Results and discussion}

\section{1. $P C B$ s powder characterization}

SEM micrographs and EDS diagrams of PCBs powder before leaching revealed that the material is heterogeneous, with particles of varying sizes, shapes and textures (Figure 1).
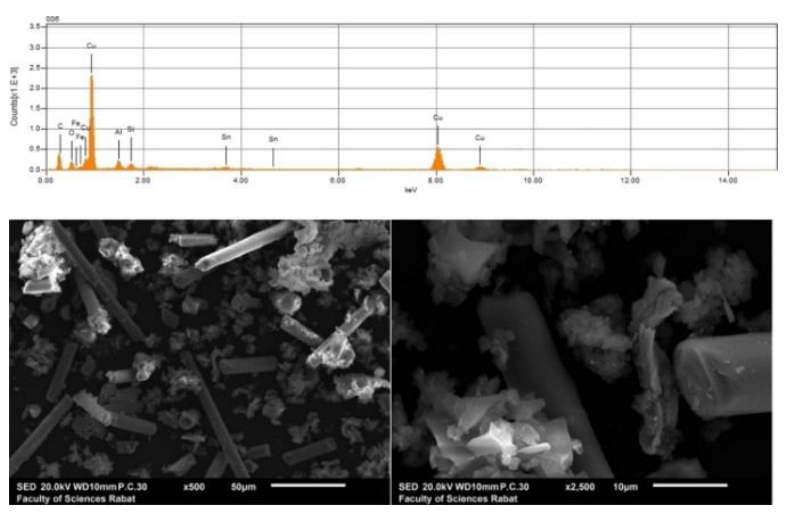

Figure 1. SEM micrographs and EDS diagram of PCBs powder before leaching
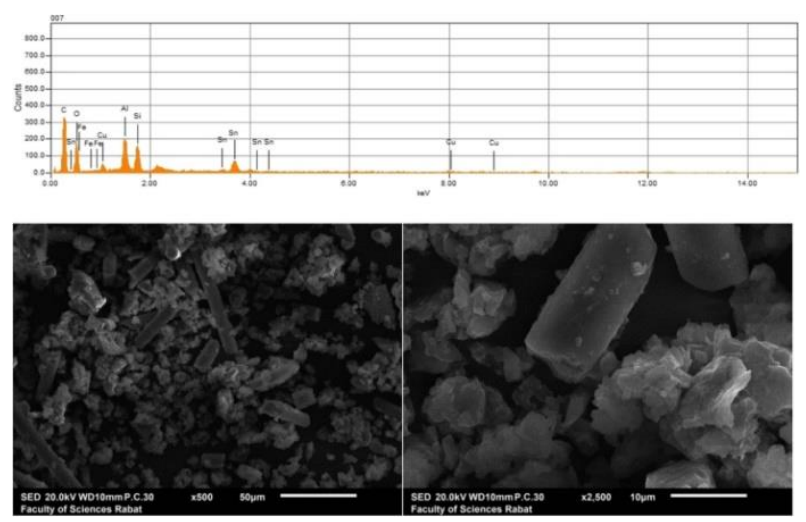

Figure 2. SEM micrographs and EDS diagram of PCBs powder after leaching with agitation for 4 days and at room temperature

Numerous particles demonstrated rod-like or polygonal shapes, with flakes on the surfaces, characteristic for an end-product of pulverization. EDS analysis shows also that the PCBs powder contain copper as a major metal and substantial non-metallic silicon and carbon fragments, materials which are commonly used in printed circuit boards. After leaching, SEM micrographs and EDS diagrams (Figure 2) of PCBs powder show that the surfaces of the material had eroded and the amount of copper has decreased very significantly.

Figure 3 shows the XRD spectrum of PCBs powder before leaching.

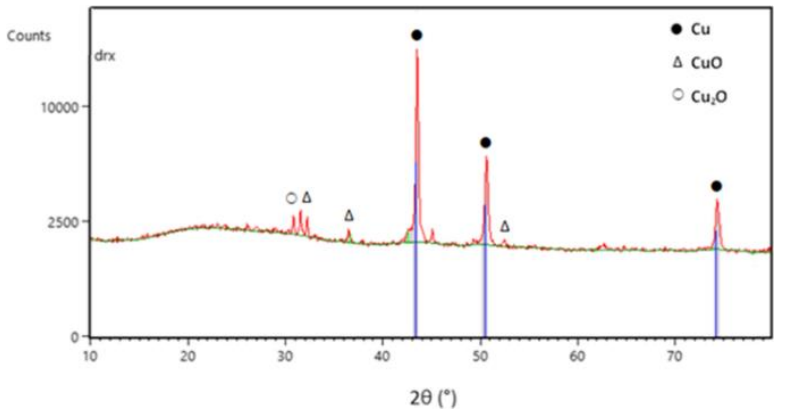

Figure 3. XRD spectrum of PCBs powder before leaching

The spectrum shows that copper is present mainly as metallic copper. Table 2 presents the result of X-ray fluorescence analysis of PCBs powder before leaching.

Copper is the major metal with a percentage of $28 \% \mathrm{w} / \mathrm{w}$. However, it must be taken into consideration that the percentage of metals in PCBs may vary according to their age, origin, manufacturer and the parts being analyzed (Guimarães et al., 2014). The percentage of copper found is in the range of values usually cited in the literature, i.e. between $10 \%$ and $30 \%$ (Oishi et al., 2007). Table 3 presents the result of X-ray fluorescence analysis of residue from PCBs powder after leaching, with agitation for 4 days and at room temperature.

The percentage of copper in PCBs powder has decreased very significantly after leaching, while the percentage of other metals has remained practically unchanged. This result demonstrates the selectivity of the leaching solution for copper. The selectivity of glycine for copper has already been highlighted by other authors. Thus Oraby and Eksteen (2014) used glycine solutions in a process for the selective 
leaching of copper from a gold-copper concentrate that comes from an ore. Aksu and Doyle (2002b) also studied the role of glycine in the chemical mechanical planarization of copper, they showed that glycine can improve the

Table 2. Composition of PCBs powder before leaching

\begin{tabular}{cccccccccc}
\hline Compositions & \multicolumn{10}{c}{ Metals } & Organics, minors \\
\hline Elements & $\mathbf{C u}$ & $\mathrm{Fe}$ & $\mathrm{Sn}$ & $\mathbf{A l}$ & $\mathbf{P b}$ & $\mathbf{A g}$ & $\mathrm{Zn}$ & $\mathbf{N i}$ & \\
\hline Content, wt.\% & 28.05 & 4.04 & 4.01 & 3.49 & 0.72 & 0.31 & 0.22 & 0.02 & 59.14 \\
\hline
\end{tabular}

Table 3. Composition of PCBs powder after leaching, with agitation for 4 days at room temperature. Glycine concentration $1 \mathrm{M}$

\begin{tabular}{cccccccccc}
\hline Compositions & \multicolumn{1}{c}{ Metals } & \multicolumn{1}{c}{ Organics, minors } \\
\hline Elements & $\mathrm{Cu}$ & $\mathrm{Fe}$ & $\mathrm{Sn}$ & $\mathrm{Al}$ & $\mathbf{P b}$ & $\mathbf{A g}$ & $\mathrm{Zn}$ & $\mathbf{N i}$ & \\
\hline Content, wt.\% & 2.88 & 4.98 & 5.21 & 4.43 & 0.95 & 0.43 & 0.3 & 0.02 & 80.8 \\
\hline
\end{tabular}

\subsection{Leaching mecanism}

The selectivity of glycine for $\mathrm{Cu}(\mathrm{II})$ ions during leaching can be explained by the values of the stability constants of the complexes that glycine can form with the different metals present in PCBs powder listed in Table 4 (Smith and Martell, 1976).

Table 4. Stability constants of glycine complexes with the main metals present in $\mathrm{PCBs}$ powder at $25^{\circ} \mathrm{C}$ and $1 \mathrm{~atm}$

\begin{tabular}{cc}
\hline Reaction & LogK \\
\hline $\mathrm{Cu}^{2+}+2 \mathrm{~L}^{-}=\mathrm{CuL}_{2}$ & 15.64 \\
\hline $\mathrm{Fe}^{2+}+2 \mathrm{~L}^{-}=\mathrm{FeL}_{2}$ & 7.65 \\
\hline $\mathrm{Fe}^{3+}+\mathrm{L}^{-}=\mathrm{FeL}^{2+}$ & 10 \\
\hline $\mathrm{Pb}^{2+}+2 \mathrm{~L}^{-}=\mathrm{PbL}_{2}$ & 7.7 \\
\hline $\mathrm{Ag}^{+}+2 \mathrm{~L}^{-}=\mathrm{AgL}_{2}^{-}$ & 6.89 \\
\hline $\mathrm{Zn}^{2+}+2 \mathrm{~L}^{-}=\mathrm{ZnL}_{2}$ & 9.81 \\
\hline
\end{tabular}

It appears that among all the complexes that glycine forms with other metal ions ( $\mathrm{Fe}, \mathrm{Pb}, \mathrm{Zn}, \ldots)$, the glycine-copper complex $\left(\mathrm{CuL}_{2}\right)$ has the highest stability constant value (Table 4). In addition, copper is the main metal (28\%) among all the metals present in PCBs powder. These two factors can explain the selectivity of glycine for copper in the leaching process.

In addition to its selectivity for copper, glycine has other characteristics. Indeed, Skrypnikovan et al. (2008), by studying copper anodic behavior in alkaline solutions with glycine additives, noted that glycine facilitates the copper oxidation. They showed that in alkaline solution and in the absence of glycine there is formation of a passive oxide/hydroxide film of complex composition $\left(\mathrm{Cu}_{2} \mathrm{O}, \mathrm{CuOH}\right.$, $\mathrm{CuO}$ and $\mathrm{Cu}(\mathrm{OH})_{2}$ ) on the surface of the copper, responsible for the passivity of the metal. On the other hand, the presence of glycine in sufficient concentration stimulates anodic processes and accelerates the anodic oxidation process of copper.

During our leaching experiments, the suspension formed by PCBs powder and the leaching solution remains in contact with the air all the time, which allows the dissolution of the oxygen of the air inside the suspension. First, the copper is oxidized by dissolved oxygen on the surface of the metallic copper (equation 2). Then the freshly formed copper oxide is further dissolved by the leaching solution (equation 3 ). planarization efficiency due to its selectivity for copper, while limiting the formation of copper oxide films during the process. 


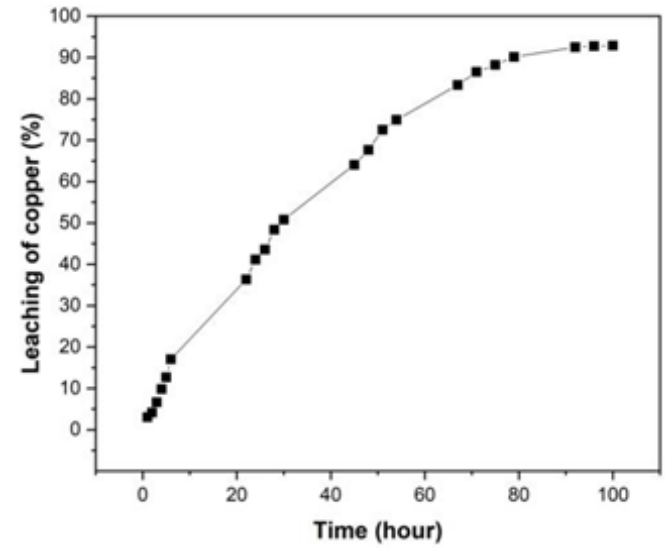

Figure 4. Evolution of copper leaching from PCBs powder over time, with mechanical agitation (700 rpm) for 4 days and at room temperature $\left(20^{\circ} \mathrm{C}\right)$. Glycine concentration $0.5 \mathrm{M}$. Solid-toliquid ratio 1:60

\subsubsection{Effect of solid-to-liquid ratio}

Figure 5 shows the evolution of copper leaching from PCBs powder over time, for several values of solid-to-liquid ratio.
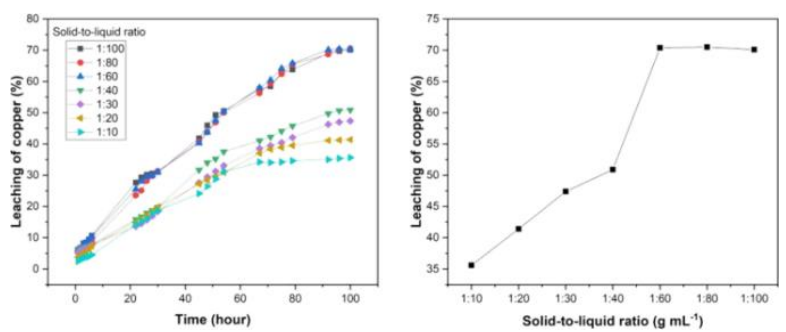

Figure 5. Effect of the solid-to-liquid ratio on copper leaching for 4 days. Mechanical stirring rate $700 \mathrm{rpm}$. Glycine concentration $1 \mathrm{M}$. Ambient temperature $\left(20^{\circ} \mathrm{C}\right)$

It was observed that leaching efficiency increased as the solid-to-liquid ratio increased from $1: 10$ to $1: 100$. When the solid-to-liquid ratio reached $1: 60$, the copper leaching efficiency reached up to $70 \%$; and beyond this ratio, no clear benefit was observed. This can be explained by the fact that the complexing agent is present in the solution more than the amount required for the leaching reaction and, therefore, the variation in the solid-to-liquid ratio did not affect the leaching efficiency. Kim et al. (2003) have made the same observation when studying the effect of the liquid-to-solid ration on the extraction of lead from soil and explained that no effective increase in extraction efficiency can be observed above a certain liquid-to-solid value. Given the copper leaching efficiency, the optimal solid/liquid ratio was chosen at 1:60.

\subsubsection{Effect of mechanical stirring}

Figure 6 shows the evolution of copper leaching from PCBs powder over time for several values of mechanical stirring.

Figure 6 shows that increased mechanical agitation resulted in better recovery of copper from the PCBs powder. Leaching efficiency increased as the mechanical stirring rate increased from 0 to $950 \mathrm{rpm}$. When the mechanical stirring rate reached $700 \mathrm{rpm}$, the copper leaching efficiency reached $92.8 \%$; above this rate, the leaching efficiency does not increase further. It can be said that mechanical stirring improves the kinetics of leaching by improving the mixing of materials and accelerating the mass transfer which increases the percentage of copper leaching in a very significant way. Considering the copper leaching efficiency, $700 \mathrm{rpm}$ was chosen as the optimal mechanical stirring rate.
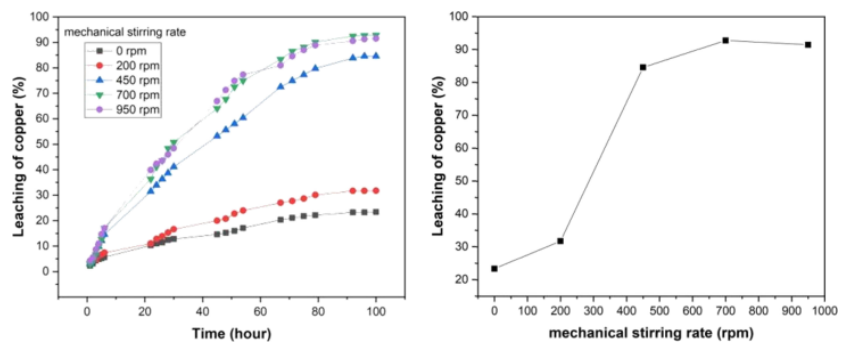

Figure 6. Effect of mechanical stirring on copper leaching for 4 days. Temperature $\left(20^{\circ} \mathrm{C}\right)$. Glycine concentration $0.5 \mathrm{M}$. Solid-toliquid ratio 1:60.

\subsubsection{Effect of leaching temperature}

Figure 7 shows the evolution of copper leaching from PCBs powder over time, for different temperatures.
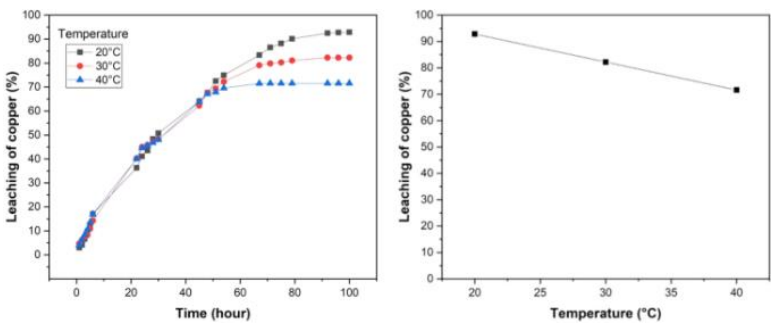

Figure 7. Effect of leaching temperature on copper leaching for 4 days. Mechanical stirring rate $700 \mathrm{rpm}$. Glycine concentration $0.5 \mathrm{M}$. Solid-to-liquid ratio 1:60

It can be seen that as the temperature of the solution increases, there is no change for 2 days in the value of leached copper which increased with time but after 2 days it appears that the percentage of copper leaching decreases when the temperature increases. the percentage of copper leaching decreases. This decrease in leaching efficiency is accompanied by a change in the colour of the solution from blue $\left(20^{\circ} \mathrm{C}\right)$ to green $\left(30^{\circ} \mathrm{C}\right)$ to very dark green $\left(40^{\circ} \mathrm{C}\right)$. Other authors have made a similar observation and found that the percentage of copper leaching from waste mobile phone PCBs, using chlorine as an oxidant, decreases with increasing temperature ${ }^{7)}$. The results found by the present study can be explained by the enthalpies values of the reactions between $\mathrm{Cu}(\mathrm{II})$ ions and glycine (Nagypal et al., 1974):

$$
\begin{aligned}
& \mathrm{Cu}^{2+}+\mathrm{L}^{-} \leftrightarrow \mathrm{CuL}^{+} \quad\left(\Delta H=-5.9 \mathrm{Kcalmol}^{-1}\right) \\
& \mathrm{CuL}^{+}+\mathrm{L}^{-} \leftrightarrow \mathrm{CuL}_{2} \quad\left(\Delta H=-7.6 \mathrm{Kcalmol}^{-1}\right) \\
& \mathrm{Cu}^{2+}+2 \mathrm{~L}^{-} \leftrightarrow \mathrm{CuL}_{2} \quad\left(\Delta H=-13.5 \mathrm{Kcalmol}^{-1}\right)
\end{aligned}
$$


The values of the enthalpies are negative, which indicates that these reactions are exothermic; an increase in temperature will have the effect of changing the reaction in the opposite direction, leading to the conversion of product into reagent (Le Chatelier's Principle). Thus, the more the leaching solution is heated, the more the copper leaching is inhibited.

\subsubsection{Effect of glycine concentration}

Figure 8 shows the evolution of copper leaching from PCBs powder over time, for different values of glycine concentration.
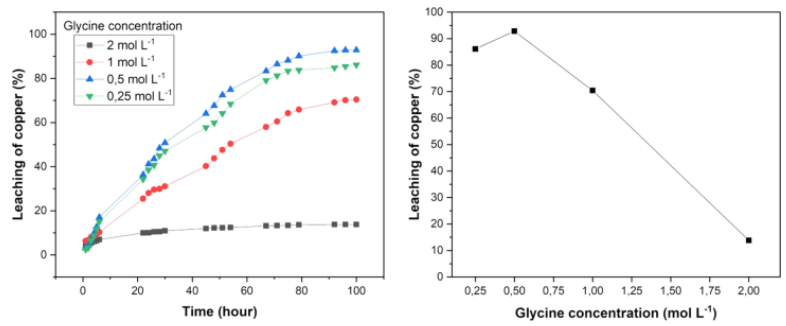

Figure 8. Effect of glycine concentration on copper leaching for 4 days. Mechanical stirring rate $700 \mathrm{rpm}$. Solide-to-liquide ratio $1: 60$. Ambient temperature $\left(20^{\circ} \mathrm{C}\right)$

It was observed that the efficiency of copper leaching increased with increasing glycine concentration from 0.25 $\mathrm{M}$ to $0.5 \mathrm{M}$. Above $0.5 \mathrm{M}$, however, copper leaching efficiency decreased. This may be indicates the appearance of other reactions that become more predominant than the glycine complexation with $\mathrm{Cu}^{2+}$ ions with the glycine concentration increased above 0.5 M. Yang et al. (2012) have made the same observation when studying the recovery of ultrafine copper particles from metal components of waste printed circuit boards using ammonia-ammonium sulfate. They found that the copper leaching efficiency increased as the ammonia concentration was increased from $0 \mathrm{M}$ to $2 \mathrm{M}$. Beyond $2 \mathrm{M}$, however, the copper leaching efficiency decreased. In our study and given the copper leaching efficiency, the optimal glycine concentration was chosen at $0.5 \mathrm{M}$.

\section{Conclusions}

In this research, the selective leaching of copper from waste printed circuit boards (PCBs) using glycine as a complexing agent was investigated. PCBs were pulverized and sieved, which allowed obtaining a PCBs powder of particle size fraction $\leq 1 \mathrm{~mm}$. The PCBs powder has been characterized by several techniques before and after leaching. In order to understand the copper extraction process, the reaction mechanisms, and to determine the optimal leaching parameters, the effects of a range of parameters during copper leaching were investigated, including leaching time, the solid-to-liquid ratio, the mechanical stirring rate, leaching temperature and glycine concentration. On the basis of the experimental results, the following conclusions have been obtained:

(1) Powder obtained by pulverization of PCBs collected from obsolete computers is a heterogeneous material, with particles of varying sizes, shapes and textures.
Copper is the major metal in PCBs powder with an average percentage of $28 \% \mathrm{w} / \mathrm{w}$;

(2) Several techniques used to characterize the residue from PCBs powder after leaching in a buffered solution (glycine, sodium carbonate) show a very significant decrease in the percentage of copper;

(3) Glycine shows a very significant selectivity for copper during leaching, so copper is dissolved in the form of CuL2 complex;

(4) Copper leaching from PCBs waste powder is a complex 4-stage gas-liquid-solid process that is carried out slowly under ambient conditions;

(5) Copper leaching from PCBs waste powder of particle size $\leq 1 \mathrm{~mm}$, with a leaching time of 4 days, a mechanical stirring rate of $700 \mathrm{rpm}$, a solid-to-liquid ratio of 1:60, a glycine concentration of $0.5 \mathrm{M}$ and at ambient conditions of temperature and atmosphere makes it possible to dissolve the copper with a percentage of $92.8 \%$.

(6) Glycine is a non-toxic, inexpensive and ecologically stable complexant which can be used in a hydrometallurgical process to recover selectively the copper contained in PCBs with a high percentage of $92.8 \%$ in the ambient conditions of temperature and atmosphere.

\section{References}

Aksu S. and Doyle F.M. (2002a), Electrochemistry of Copper in Aqueous Ethylenediamine Solutions, Journal of The Electrochemical Society, 149(7), B340.

Aksu S. and Doyle F.M. (2002b), The Role of Glycine in the Chemical Mechanical Planarization of Copper, Journal of The Electrochemical Society, 149(6), G352.

Baldé C.P., Forti V., Kuehr R., Bel G. (2020), The Global E-waste Monitor 2020, Quantities, Flows, and The circular economy potential, United Nations University (UNU). United Nations Institute for Training and Research (UNITAR) - co-hosted SCYCLE Programme, International Telecommunication Union (ITU) \& International Solid Waste Association (ISWA), Bonn/Geneva/Rotterdam.

Bigum M., Brogaard L. and Christensen T.H. (2012), Metal recovery from high-grade WEEE: a life cycle assessment, Journal of Hazardous Materials, 207-208, 8-14.

Büyükbay B., Ciliz N., Goren G.E. and Mammadov A. (2010), Cleaner production application as a sustainable production strategy, in a Turkish Printed Circuit Board Plant, Resources, Conservation and Recycling, 54(10), 744-751.

Cui J. and Zhang L. (2008), Metallurgical recovery of metals from electronic waste: a review, Journal of Hazardous Materials, 158(2-3), 228-256.

Drissi-Daoudi R., Irhzo A. and Darchen A. (2003), Electrochemical investigations of copper behaviour in different cupric complex solutions: Voltammetric study, Journal of Applied Electrochemistry, 33, 339-343.

Duan C., Wen X., Shi C., Zhao Y., Wen B. and He Y. (2009), Recovery of metals from waste printed circuit boards by a mechanical method using a water medium, Journal of Hazardous Materials, 166(1), 478-482. 
Goosey M. and Kellner R. (2003), Recycling technologies for the treatment of end of life printed circuit boards (PCBs), Circuit World, 29(3), 33-37.

Guimarães Y.F., Santos I.D. and Dutra A.J.B. (2014), Direct recovery of copper from printed circuit boards (PCBs) powder concentrate by a simultaneous electroleachingelectrodeposition process, Hydrometallurgy, 149, 63-70.

Guo C., Wang H., Liang W., Fu J. and Yi X. (2011), Liberation characteristic and physical separation of printed circuit board (PCB), Waste Management, 31(9-10), 2161-2166.

Havlik T., Orac D., Petranikova M., Miskufova A., Kukurugya F. and Takacova Z. (2010), Leaching of copper and tin from used printed circuit boards after thermal treatment, Journal of Hazardous Materials, 183(1-3), 866-873.

Jha M.K., Kumari A., Choubey P.K., Lee J., Kumar V. and Jeong J. (2012), Leaching of lead from solder material of waste printed circuit boards (PCBs), Hydrometallurgy, 121-124, 28-34.

Kiddee P., Naidu R. and Wong M.H. (2013), Electronic waste management approaches: An overview, Waste Management, 33(5), 1237-1250.

Kim C., Lee Y. and Ong S.K. (2003), Factors affecting EDTA extraction of lead from lead-contaminated soils, Chemosphere, 51(9), 845-853.

Kim E., Kim M., Lee J. and Pandey B.D. (2011), Selective recovery of gold from waste mobile phone PCBs by hydrometallurgical process, Journal of Hazardous Materials, 198, 206-215.

Koyama K., Tanaka M. and Lee J. (2006a), Copper Leaching Behavior from Waste Printed Circuit Board in Ammoniacal Alkaline Solution, Materials Transactions, 47(7), 1788-1792.

Koyama K., Tanaka M., Miyasaka Y. and Lee J. (2006b), Electrolytic Copper Deposition from Ammoniacal Alkaline Solution Containing Cu(I), Materials Transactions, 47(8), 2076-2080.

Masavetas I., Moutsatsou A., Nikolaou E., Spanou S., Pavlatou E.A. and Spyrellis N. (2009), Production of copper powder from printed circuit boards by electrodeposition, Global NEST, 11(2), 241-247.

Mokhlis H., Drissi-Daoudi R., Azzi M. (2018), Procédé de récupération sélective du cuivre à partir des déchets d'équipements électriques et électroniques en solution de glycine, MA Patent 43484A1.

Nagypal I., Gergely A. and Farkas E. (1974), Thermodynamic study of the parent and mixed complexes of aspartic acid, glutamic acid and glycine with copper(II), Journal of Inorganic and Nuclear Chemistry, 36(3), 699-706.

Oguchi M., Murakami S., Sakanakura H., Kida A. and Kameya T. (2011), A preliminary categorization of end-of-life electrical and electronic equipment as secondary metal resources, Waste Management, 31(9-10), 2150-2160.

Oishi T., Koyama K., Alam S., Tanaka M. and Lee J.-C. (2007), Recovery of high purity copper cathode from printed circuit boards using ammoniacal sulfate or chloride solutions, Hydrometallurgy, 89(1-2), 82-88.

Oraby E.A. and Eksteen J.J. (2014), The selective leaching of copper from a gold-copper concentrate in glycine solutions, Hydrometallurgy, 150, 14-19.

Oraby E.A. and Eksteen J.J. (2015), The leaching of gold, silver and their alloys in alkaline glycine-peroxide solutions and their adsorption on carbon, Hydrometallurgy, 152, 199-203.

Oraby E.A., Eksteen J.J. and Tanda B.C. (2017), Gold and copper leaching from gold-copper ores and concentrates using a synergistic lixiviant mixture of glycine and cyanide, Hydrometallurgy, 169, 339-345.

Rocchetti L., Amato A. and Beolchini F. (2018), Printed circuit board recycling: A patent review, J. Clean. Prod, 178 814-832.

Salhofer S. and Tesar M. (2011), Assessment of removal of components containing hazardous substances from small WEEE in Austria, Journal of Hazardous Materials, 186(2-3), 1481-1488.

Singhal P. (2005), Integrated Product Policy Pilot Project Stage I Final Report: Life Cycle Environmental Issues of Mobile Phones, Nokia: Espoo, 358(April), 81.

Skrypnikova E.A., Kaluzhina S.A. and Popova E.V. (2008), Peculiarities of Copper Anodic Behavior in Alkaline Solutions with Glycine Additives, $E C S$ Transactions, The Electrochemical Society, 13(27), 7-12.

Smith R.M. and Martell A.E. (1989), Critical Stability Constants, Volume 6: Second Supplement, Springer Science and Business Media New York.

Sun Z.H.I., Xiao Y., Sietsma J., Agterhuis H., Visser G. and Yang Y. (2015), Selective copper recovery from complex mixtures of end-of-life electronic products with ammonia-based solution, Hydrometallurgy, 152, 91-99.

Tuncuk A., Stazi V., Akcil A., Yazici E.Y. and Deveci H. (2012), Aqueous metal recovery techniques from e-scrap: Hydrometallurgy in recycling, Minerals Engineering, 25(1), 28-37.

Vijayaram R., Chandramohan K. (2013), Studies on Metal (Cu and Sn) Extraction from the Discarded Printed Circuit Board by Using Inorganic Acids as Solvents, Journal of Chemical Engineering \& Process Technology, 4(2), 2-4.

Xiao Y., Yang Y., Van Den Berg J., Sietsma J., Agterhuis H., Visser G. and Bol D. (2013), Hydrometallurgical recovery of copper from complex mixtures of end-of-life shredded ICT products, Hydrometallurgy, 140, 128-134.

Xiu F.-R., Qi Y. and Zhang F.-S. (2013), Recovery of metals from waste printed circuit boards by supercritical water pretreatment combined with acid leaching process, Waste Management, 33(5), 1251-1257.

Yang J.G., Wu Y.T. and Li J. (2012), Recovery of ultrafine copper particles from metal components of waste printed circuit boards, Hydrometallurgy, 121-124, 1-6.

Yang T., Xu Z., Wen J. and Yang L. (2009), Factors influencing bioleaching copper from waste printed circuit boards by Acidithiobacillus ferrooxidans, Hydrometallurgy, 97(1-2), 2932.

Yang X., Sun L., Xiang J., Hu S. and Su S. (2013), Pyrolysis and dehalogenation of plastics from waste electrical and electronic equipment (WEEE): A review, Waste Management, 33(2), 462-473.

Zhang Y., Liu S., Xie H., Zeng X. and Li J. (2012), Current Status on Leaching Precious Metals from Waste Printed Circuit Boards, Procedia Environmental Sciences, 16, 560-568.

Zhou Y. and Qiu K. (2010), A new technology for recycling materials from waste printed circuit boards, Journal of Hazardous Materials, 175(1-3), 823-828.

Zhu N., Xiang Y., Zhang T., Wu P., Dang Z., Li P. and Wu J. (2011), Bioleaching of metal concentrates of waste printed circuit boards by mixed culture of acidophilic bacteria, Journal of Hazardous Materials, 192(2), 614-619. 